IZA DP No. 9708

Peer Effects in Employment Status:

Evidence from Housing Lotteries for

Forced Evacuees in Fukushima

Ayako Kondo

Masahiro Shoji

February 2016 


\title{
Peer Effects in Employment Status: Evidence from Housing Lotteries for Forced Evacuees in Fukushima
}

\author{
Ayako Kondo \\ Yokohama National University \\ and IZA \\ Masahiro Shoji \\ Seijo University \\ Discussion Paper No. 9708 \\ February 2016 \\ IZA \\ P.O. Box 7240 \\ 53072 Bonn \\ Germany \\ Phone: +49-228-3894-0 \\ Fax: +49-228-3894-180 \\ E-mail: iza@iza.org
}

Any opinions expressed here are those of the author(s) and not those of IZA. Research published in this series may include views on policy, but the institute itself takes no institutional policy positions. The IZA research network is committed to the IZA Guiding Principles of Research Integrity.

The Institute for the Study of Labor (IZA) in Bonn is a local and virtual international research center and a place of communication between science, politics and business. IZA is an independent nonprofit organization supported by Deutsche Post Foundation. The center is associated with the University of Bonn and offers a stimulating research environment through its international network, workshops and conferences, data service, project support, research visits and doctoral program. IZA engages in (i) original and internationally competitive research in all fields of labor economics, (ii) development of policy concepts, and (iii) dissemination of research results and concepts to the interested public.

IZA Discussion Papers often represent preliminary work and are circulated to encourage discussion. Citation of such a paper should account for its provisional character. A revised version may be available directly from the author. 
IZA Discussion Paper No. 9708

February 2016

\section{ABSTRACT}

\section{Peer Effects in Employment Status: Evidence from Housing Lotteries for Forced Evacuees in Fukushima*}

Does a high peer employment rate increase individual employment probability? We exploit the random assignment of temporary housing to evacuees from the Fukushima Daiichi nuclear power plant accident to identify the effect of neighbors' employment rates on an individual's probability of finding a job post-evacuation. Using unique survey data collected in 14 clusters of temporary housing 2.5 years after the accident, we find a significantly positive peer effect: a one standard deviation increase in the initial employment rate of an individual's peers makes the hazard of restarting work 1.53 times larger during the six months after housing move-in.

JEL Classification: J20, J64

Keywords: peer effect, neighborhood effect

Corresponding author:

Ayako Kondo

Faculty of International Social Sciences

Yokohama National University

79-4 Tokiwadai, Hodogaya, Yokohama

Kanagawa, 240-8501

Japan

E-mail: akondo@ynu.ac.jp

\footnotetext{
* Japan Society for the Promotion of Science KAKENHI Grants Number 25780172 (PI: Masahiro Shoji) and 15K17072 (PI: Ayako Kondo) supported this research. The authors are grateful to the Iwaki Liaison Council to Support the Disaster-Victims of 3.11 for their valuable cooperation in the household survey.We also thank Daniel Hamermesh, Shin Kanaya, Ryo Nakajima, Koyo Miyoshi, seminar participants at the $8^{\text {th }}$ Trans Pacific Labor Seminar, Hitotsubashi University, the $11^{\text {th }}$ World Congress of the Econometric Society, the Workshop on Natural Disasters, the Kyoto Summer Workshop on Applied Economics, Hitotsubashi Summer Institute on Labor Economics, the National Institute of Population and Social Security Research, Tohoku University, University of Tsukuba, and Otaru University of Commerce for many constructive suggestions.
} 


\section{Introduction}

Does a high employment rate among an individual's neighbors increase that individual's employment probability? Previous studies have shown that neighborhood quality is strongly correlated with an individual's labor market outcomes (Borjas 1995, Cutler and Glaeser 1997, Weinberg, Reagan, and Yankow 2004). However, well-known problems such as self-sorting of peers, common shocks, and the reflection problem (Manski 1993, 2000) make it difficult to identify a causal effect of the peer employment rate. Although a few recent studies attempt to solve these problems by use of an instrumental variable for peer employment status (Maurin and Moschion 2009), unlike peer effects in student outcomes or workplace productivity, ${ }^{1}$ experimental evidence from randomly assigned peers is still scarce in the context of peer effects in employment. ${ }^{2}$

We exploit the random assignment of temporary housing to evacuees from the Fukushima Daiichi nuclear power plant accident to identify the effect of the neighbors' employment rate on the probability of finding a job after the evacuation. After the accident caused by the Great East Japan Earthquake and the subsequent tsunami, people living within a $30-\mathrm{km}$ radius of the plant were forced to evacuate to other municipalities. Several months later, many of these evacuees were moved from emergency shelters to publicly provided temporary housing units allocated by government lottery. This situation provides a rare opportunity to examine the causal effect of the peer employment rate using randomly assigned neighbors.

We use unique survey data collected in 14 clusters of temporary housing 2.5 years after the accident. Among the 588 sample individuals aged 20-69 years, 480 were not employed as of the end

\footnotetext{
${ }^{1}$ Random assignment of classmates and college roommates is widely used in the literature of peer effects on student behaviors; Sacerdote (2014) provides a comprehensive survey. Also, there is a growing body of literature to utilize random assignment of peers to examine peer effects on other outcomes such as worker productivity (Mas and Moretti 2009, Bandiera, Brankay, and Rasul 2010) and crime (Bayer, Hjalmarsson, and Pozen 2009).

2 The only exception that we are aware of is the study by Lanschever (2009), which shows a significant peer effect in employment among those who were in the same company during World War I. This paper differs from Lanschever's study in three important aspects: First, we examine shorter-term effect, namely, within a few years since the evacuation, whereas he examines the outcome as of 1930 (more than ten years after the end of the war) Second, our sample includes women and elderly citizens, while his sample is limited to males in their 20s to 40s. Third, as we discuss more in Section 6.3, the peer effect among geographical neighbors might be different from that among ex-coworkers.
} 
of March 2011, the month when the power plant accident occurred. We use a sample of these evacuees to estimate the effect of the ratio of neighbors who had already been working before moving to temporary housing on the length of time until the unemployed evacuees restarted work. We find a significantly positive peer effect that is robust to various controls for individual characteristics and housing cluster fixed effects. The effect is not only statistically significant, but also economically substantial: a one standard deviation (16 percentage points) increase in the initial employment rate of an individual's peers makes the hazard of restarting work 1.53 times larger during the first six months after housing move-in.

This paper relates to the growing literature on neighborhood effects and help reconciling the apparently contradicting results of existing studies. On the one hand, existing studies on job information networks point out the importance of referrals from neighbors (Ioannides and Loury 2004). Also, studies that attempt to solve reflection problems by use of an instrumental variable for neighbors’ employment status (Maurin and Moschion 2009) or controls for various fixed effects to absorb self-sorting of neighbors (Bayer, Ross and Topa 2008) tend to find significant peer effects on employment. On the other hand, Kling, Liebman, and Katz (2007) examine the Moving to Opportunity Program (MTO), a social experiment to let randomly picked residents of public housing in poor neighborhoods move to better neighborhoods, and find insignificant effects of neighborhood quality on adults’ employment.

Our finding of a significantly positive peer effect in employment status among randomly assigned peers suggests that the apparent contradiction between the two strands of literature is not attributable to the difference in the research design (randomized experiment vs. non-experiment). Instead, the significance of the peer effect may depend on the degree to which the randomly assigned residents can maintain their sense of community in the new neighborhood. ${ }^{3}$ Beneficiaries of the

\footnotetext{
3 Indeed, Gould et al. (2011) study the random assignment of residences to Yemenite immigrants in Israel, who presumably maintained some sense of Yemenite community after immigration; they found a significant long-term impact of childhood living environment on many socioeconomic outcomes in adulthood, such as educational attainment. In contrast, Barnhardt et al. (2015) study winners of the housing lottery in India, who were provided improved housing to move out of the slums, and find that the winners report no change in family income or human
} 
MTO must migrate to regions geographically and socioeconomically different from where they previously resided, and they would be expected to have less social interaction with the region's original residents. In contrast, in the case of temporary housing in Fukushima, all residents of a temporary housing cluster are from the same municipality, and this process helps maintain their sense of community. They would tend to communicate with each other and be concerned about their social image; these are important drivers of peer effects.

This study also contributes to the post-disaster rehabilitation policy literature. Disasters cause increases in the unemployment rate (Groen and Polivka 2008), and this is a critical concern among policymakers (US Bureau of Labor Statistics 2006). However, few empirical studies argue how employment can be recovered. Our findings suggest that social interactions with employed individuals could significantly facilitate reemployment.

The remainder of this paper is organized as follows: Section 2 introduces the detailed process of housing lotteries and how we define the peer group. Section 3 describes data and summary statistics. The empirical strategy to estimate the peer effects and the results are presented in Sections 4 and 5, respectively, and Section 6 provides further discussion about employment opportunities available for the evacuees, the potential effect from financial compensation, and underlying mechanisms for the observed peer effect. Section 7 provides concluding remarks.

\section{Background}

\subsection{Housing lotteries for the forced evacuees in Fukushima}

The Fukushima Daiichi nuclear power plant accident—caused on March 11, 2011, by the Great East Japan Earthquake and a subsequent tsunami-forced over 100,000 citizens to evacuate. Citizens of the municipalities within a 30-km radius of the power plant were ordered to evacuate to outside the area; therefore, most of them headed to large cities in Fukushima, such as the cities of Iwaki, Aizu, and Koriyama.

capital and increased isolation from family and caste networks after 14 years. 
Our study site is Iwaki city, which is $30-60 \mathrm{~km}$ from the Fukushima Daiichi nuclear power plant. Iwaki is one of the municipalities that accepted a large number of forced evacuees. While the city hosts 36 clusters of publicly provided temporary housing for 3,500 households, the housing for tsunami-affected Iwaki citizens amounts to only around 180 housing units. The remainders are for forced evacuees from six radiation-affected municipalities: Futaba, Okuma, Tomioka, Naraha, Hirono, and Kawauchi. ${ }^{4}$

In Iwaki city, the provision of temporary housing was slow and gradual due to the vast amount of required housing and limited land availability. Although the occupancy of the first cluster was completed in May 2011, some clusters were still under construction even in the summer of 2012. While awaiting the construction of temporary housing, the evacuees had to stay at emergency shelters such as schools and public halls. Given this delay in housing provision, some of the evacuees started to work before moving into the temporary housing.

The allocation procedure of temporary housing for the forced evacuees has two important features for our identification of peer effects in employment. First, each municipality held the right-to-use of a few clusters in Iwaki. Hence, all residents of a housing cluster were from the same municipality. Second, the municipal governments used a lottery to allocate housing to its citizens. When the construction of a housing cluster was completed, evacuees from the municipality that held the right-to-use could apply for that housing. The location of housing within the cluster was also randomly allocated through the lottery. Those who were selected through the lottery could move in, and most of them moved in within a few months. Those who were not selected had to wait for the next lottery opportunity.

This set of circumstances provides us with a natural experimental situation to identify the peer effect in employment status. Since the residents of clusters are randomly selected, the

\footnotetext{
${ }^{4}$ While the evacuation orders for Kawauchi and Hirono were lifted in January and March 2012, respectively, as of September 2013, when our data were collected, most evacuees still kept evacuating; only around 20 percent of citizens had returned to Hirono, and most of these citizens were elderly. Regarding Kawauchi, there was no official statistics on the rate of return until June 2014.
} 
employment status of neighbors at the time of moving into their cluster is exogenously given. Furthermore, the neighbors are originally from the same municipality. This helps ensure their sense of community, and therefore promotes active social interactions among the residents. By leveraging these circumstances, we can estimate the impact of employment rate among peers at the time of moving into the cluster on the probability that the initially unemployed evacuees restart work.

\subsection{Definition and measurement of peers' employment}

We define each individual's “peer group” as his or her neighbors living in the same block (subcluster), except for his or her own family members living in the same house. On average, each housing cluster is divided into 3.8 blocks, with around 34 households per block. As an example, Figure 1 shows a map of Rinjo cluster, one of the clusters in our sample, with 106 housing units divided into 4 blocks (A-D). To give a specific image of the peer group, let us use a person living in housing unit A1-1. The peer group for this person is defined as those living in the 40 housing units in block A, except for his or her own family members living in A1-1.

[Insert Figure 1 about here]

By defining peer groups at the block level, we can control for cluster characteristics, such as the timing of construction, geographic characteristics, and which municipality has a right-to-use. These factors might cause spurious correlation between the peer employment rate and the individual's own probability of taking a job after moving into the housing. For example, the residents of a cluster that was constructed later would be more likely to restart work before moving in, and if not, they could be more likely to take a job soon. By examining the block-level employment rate while controlling for cluster fixed effects, we can identify the causal effect of the neighbors' employment rate on the probability of restarting work, given the cluster characteristics constant.

Furthermore, in practice, neighbors in the same block seem to be a good approximation of the range of people with whom an individual communicates regularly. First, the randomized allocation 
of housing completely disassociated local communities that existed before the power plant accident, and thus the evacuees knew few people in the cluster when they moved in (Shoji and Akaike 2014). Therefore, it is reasonable to presume that they initially communicated with only a few adjacent households. Second, some blocks are geographically isolated from the others even within the same cluster. For example, Block A in Figure 1 is separated from the other blocks by a ditch running through the cluster. Third, the opportunities to get to know the evacuees in the other blocks are limited for working-age adults because they seldom participate in social events held by the municipality and non-governmental organizations to encourage the communication among the evacuees in the same cluster beyond blocks. Finally, there is also anecdotal evidence based on the authors' field interviews; some evacuees were unaware for a long period of time that their friends had also moved into the same cluster, because they were allocated to different blocks.

One might be still concerned about the use of neighbors at the block level. First, admittedly, individuals living near the border of blocks may communicate more with neighbors in the next block rather than people living on the other end of their own block. Appendix A1 shows robustness checks that incorporate neighbors living in the adjacent block in peer groups for those living near the border of blocks. The results do not qualitatively change. Second, in theory, a peer group could also be defined as a group of individuals with similar demographic characteristics. However, the employment rate of peers defined in this way is not independent of an individual's own characteristics, because demographic characteristics are correlated with both the individual's own and peers' employment rate. Furthermore, it is not feasible to limit the range of peers to the same demographic groups and run a separate regression for each group, because the sample size is too small.

Given these arguments, we define the initial employment rate of individual i's peers, peer $i$, as the ratio of peers who had restarted work by the month they moved into the temporary housing among all peers living in the same block at the time of the survey. Specifically, for each respondent 
aged 20-69 years, we generate a dummy indicator that takes the value of 1 if he or she had already restarted work before moving into temporary housing (i.e., the month of move-in is later than the month of restarting work). Then, we take the average of this dummy indicator of all respondents in the same block except members of the respondent's own household.

Note that the employment status of each member of the peer group is measured at the time this particular member moved in, not when individual $i$ moved in. We define peer , in this way for two reasons. First, it is independent of the individual's own characteristics. Strictly speaking, the people who should actually matter to an individual are the neighbors who were around at the time that the individual moved in, not everyone who lived in the same block as of September 2013. Additionally, peers' employment status at the time that this individual moved in would be more relevant than the status at the time each person in the peer group moved in. However, using the time that each individual moved in would make the peers' employment rate correlated with an individual's own characteristics, as the peers' employment rate increases over time. That is, people who moved in later would tend to be exposed to a higher peer employment rate. Therefore, we use the exogenous measure of peers' initial employment status.

Second, as shown later, about three quarters of our sample moved into temporary housing within two months after construction completion. Therefore, in practice, the difference between these two measures of the peer employment rate is very small. In Appendix A2, we limit our sample to those who moved within the two months following the completion of construction as a robustness check and find that results do not change qualitatively.

\section{Data}

\subsection{Survey design and sample selection}

In September 2013, we conducted a unique household survey of residents of the temporary housing clusters in Iwaki city. ${ }^{5}$ The survey households were selected using the stratified random sampling

5 As of September 2013, the occupancy rate of temporary housing in Iwaki was as high as 95.8 percent (a press 
method. In the first stage, we non-randomly selected 14 of 36 clusters based on cluster size and location and the municipality holding a right-to-use. We excluded clusters for the evacuees from tsunami-affected areas in Iwaki from our sample because their assignment to temporary housing was not based on the lottery. In the second step, approximately 50 percent of the housing was randomly selected in each cluster (a total of 784 of 1,733 housing units). In the third step, the vacant housing units were replaced with a neighbor, if available. Ultimately, we visited 701 households and completed a survey with 518 of them. ${ }^{6}$ Table 1 presents a breakdown of the municipalities of the sample households (Column (3)) among the total evacuee households in Iwaki (Column (4)); as one can see, our sample is not biased to any particular municipalities.

\section{[Insert Table 1 about here]}

Table 2 lists the housing clusters we surveyed and the number of blocks in each. The Onigoe cluster is shared with three municipalities: Kawauchi, Hirono, and Iwaki. Since the housing lottery was conducted within each municipality that occupies the housing, we treated the block occupied by Kawauchi and the three blocks occupied by Hirono as separate clusters.

\section{[Insert Table 2 about here]}

Although we interviewed one person per household, we collected basic information such as gender, age, and employment status for all individuals living in the same household. The number of all individuals included in the data is 1,117 . Among them, we limited our sample to 588 individuals aged 20-69 years. Table 3 compares the demographic composition of these 588 individuals in our data with the population of the six municipalities where the evacuees lived before the power plant accident, based on the Population Census 2010. Our sample is older than the baseline population, mainly because households with young children were more likely to move out of the region permanently or choose other options such as leased housing financed by the government. Further, the

release by Fukushima prefecture http://www.pref.fukushima.lg.jp/uploaded/life/174887_383752_misc.pdf). Thus, the potential bias caused by endogenous attrition from temporary housing is, if there is any, expected to be minimal. ${ }^{6}$ Correlation between the non-response rate at the block level and the ratio of individuals who already started to work at the time of move-in is very weak and statistically insignificant (correlation coefficient $=-0.03$, p-value $=$ $0.85)$. 
individuals in our sample are less likely to have university degrees because older cohorts are on average less educated.

[Insert Table 3 about here]

Among the 588 evacuees aged 20-69 years, 108 were working as of the end of March 2011, the month when the accident occurred. We assume they continued working at the same job and exclude them from the analyses sample, although they are included in the computation of the peer employment rate at the time of move-in.

\subsection{Variables and summary statistics}

Our main outcome variable is the hazard to restart work after the power plant accident. This variable is constructed from the month when the individual restarted working. ${ }^{7}$ Figure 2 summarizes the Kaplan-Meier survival function for the sample of those who had not yet restarted work as of the

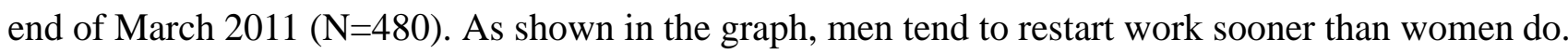
About 51.6 percent of men and 24.3 percent of women restarted work by the time the survey was conducted in September 2013. We take into account this gender-based difference in the hazard function.

\section{[Insert Figure 2 about here]}

Table 4 shows the summary statistics by employment status as of the end of March 2011. The first column includes all individuals aged 20-69 years; this is the sample used to calculate the peer employment rate. The second column includes those who had not yet restarted work as of the end of March 2011; i.e., the sample used in the main analysis. For comparison, the third column includes those who continued to work.

[Insert Table 4 about here]

\footnotetext{
7 Unfortunately, the survey did not ask for much detail on current economic situations, such as earnings, occupation and other job information as of the survey date, because such questions can offend the evacuees who were forced to leave their homes and jobs. We do not know to what extent an evacuee's current job is related to the job held before the accident, either.
} 
Panel A of Table 4 shows that those who continued working are more likely to be men, aged 40-59 years, more educated, and in larger households. On the other hand, damage to the house and loss of family members is uncorrelated with employment right after the accident. Nonetheless, we control for these variables because the level of damage from the earthquake and tsunami may affect labor supply by way of the amount of financial support provided by the government. Additionally, it may have some psychological effect. Respondents' subjective well-being is used in the analyses of underlying mechanisms in Section 6.3.

Panel B summarizes the evacuation process. On average, evacuees moved in to the temporary housing 9.5 months after the accident, and there is no difference between those who continued working and those who did not. Further, 74 percent of our sample moved into the temporary housing within the two months following its construction completion; thus, the average employment rate at the time when each person in the peer group moved in should serve as a good proxy for the average employment status of neighbors at the time the individual moved in.

Panel C summarizes an individual's own employment status and peers' employment rate. At the time of move in, about 33 percent of all evacuees aged 20-69 years had already restarted work. Among those who did not continue working right after the accident, 18 percent restarted work. As already shown in Figure 3, men are more likely to restart work than women. By the time of the survey in September 2013, 48 percent of all evacuees and 36 percent of those who did not work at the end of March 2011 had restarted work.

\section{[Insert Figure 3 about here]}

As explained in Section 2.2, our key explanatory variable is peer ${ }_{i}$, the fraction of peers who had already started to work before they moved in. This variable is calculated based on all 588 individuals. The average number of peers in our data is $15.6,{ }^{8}$ and the average peers' employment rate is 32 percent. As expected from the random assignment of peers, these variables are uncorrelated

8 Note that our data is a 50 percent random sample of the housing cluster residents, not a complete survey, and 32 percent of the survey households do not include any individuals aged 20-69 years. Thus, although the average number of housing units per block is 34 , the average number of peers in our data is 15.6 . 
with the individual's own employment status. The standard deviation is 16 percent, and Figure 4 shows the Kernel density.

[Insert Figure 4 about here]

\section{Empirical model to estimate the peer effects}

To identify the causal effect of peer - the employment rate of neighbors at the time that they moved in, as defined above-on the hazard of restarting work, we estimate the following Cox proportional hazard model:

$(1) \mathrm{h}\left(\mathrm{t} \mid\right.$ peer $\left._{i}, \operatorname{sex}_{i}, x_{i}\right)=\lambda\left(\mathrm{t} ; \operatorname{sex}_{i}\right) \exp \left(X_{i} \beta+\right.$ peer $_{i} D_{i t}^{\text {bef }} \gamma^{\text {bef }}+\operatorname{peer}_{i} D_{i t^{0}{ }^{0}} \gamma^{0-5}$

$$
\left.+\operatorname{peer}_{i} D_{i t}^{6-11} \gamma^{6 \_11}+\text { peer }_{i} D_{i t}^{1 y r} \gamma^{1 y r}\right)
$$

The hazard of restarting work, $\mathrm{h}\left(\mathrm{t} \mid\right.$ peer $\left._{i}, \operatorname{sex}_{i}, x_{i}\right)$, is the probability density associated with individual $i$ restarting work in the $t$-th month after March 2011, when the power plant accident occurred, conditional on having not resumed working since March 2011.

We allow the effect of peer $r_{i}$ to vary with the months since the individual moved in to the temporary housing cluster. Specifically, we interact with the following four dummy variables: $D_{i t}^{\text {bef }}$, $D_{i t}^{0.5}, D_{i t}^{6-11}$ and $D_{i t}^{1 y r}$ take 1 if the month $t$ is before the month of move-in for individual $i, 0-5$ th month after move in, 6-11th month after move in, and more than 1 year after move in, respectively. We expect that $\gamma^{\text {bef }}=0$ because the individual has not yet even met his or her prospective neighbors. ${ }^{9}$ Therefore, we use this as a placebo test. If the peer effect exists, $\gamma^{0 \_5}$ is expected to be positive. $\gamma^{6 \_12}$ and $\gamma^{1 y r}$ can also be positive, but they are expected to be smaller than $\gamma^{0 \_5}$ for several reasons. First, if the peer effect is heterogeneous across individuals, those who are affected by peers find a job quickly and exit from the sample, especially when peer $_{i}$ is high. Thus, those who remain in the sample after six months are likely to be irresponsive to the peer employment rate.

\footnotetext{
${ }^{9}$ For the 85 individuals who already started working before moving in to the temporary housing, peer $r_{\mathrm{i}}$ should have no effect. Nonetheless, we included them in the sample to avoid potential biases arising from left censoring of the sample. That is, if we limited our sample to those who did not start work before move-in and set the month of move-in as the starting point, the remaining sample would be non-randomly selected. We thank Daniel Hamermesh for pointing out this issue.
} 
Second, since peer $_{i}$ is measured at the time around the move-in, the difference between peer $_{i}$ and the employment rate among peers in month $t$ becomes lager over time. Hence, peer $r_{i}$ becomes less relevant.

We also allow the baseline hazard, $\lambda\left(\mathrm{t}\right.$; $\left.\mathrm{sex}_{i}\right)$, to vary across genders, because the survival functions shown in Figure 3 are quite different between men and women. The vector of control variables $X_{i}$ in the exponential part includes dummies for 10-year age categories, dummies for educational background, household size, dummies for the level of housing loss, an indicator for any loss of household members due to the tsunami or earthquake, dummies for $0-5$ th month after move in, 6-11th month after move in, and more than one year after move in, and housing cluster fixed effects. The standard errors are clustered at the housing cluster level, to allow any unobservable, time-variant common shock to apply to all households in the same housing cluster.

As Manski (1993, 2000) points out, in general settings, it is difficult to estimate the causal effect of the behaviors of an individual's peers, because self-sorting or common shocks could generate spurious correlation between an individual's and his or her peers' behaviors. That is, individuals in the same group tend to behave the same way because they have similar individual characteristics or face similar conditions. ${ }^{10}$ We solve the problem of self-sorting by exploiting the random assignment of housing locations by the lottery. Also, our estimates are not affected by the common shocks because the employment status of peers at the time of their move-in should be uncorrelated with any block-level shocks that would occur after their move-in. Furthermore, thanks to the lottery, the individuals currently living in the same block are unlikely to have experienced any common shocks before their move-in because they were randomly chosen from different temporary shelters and did not know each other until moving to the housing. Finally, by using the employment status of peers determined before they move as the main explanatory variable, we can also avoid the

\footnotetext{
10 Such spurious correlations are called a correlated effect, whereas the causal effect of peer behavior on an individual's behavior is called an endogenous effect. Manski (1993) also mentions an exogenous effect where the individual's behavior is influenced by pre-determined characteristics of peer group members, which also influence other members' behaviors; however, existence of such effect is not very plausible in our context.
} 
problem of simultaneity, or the reflection problem.

The key assumption for our identification strategy is that the assignment of temporary housing is actually random. The random assignment of housing predicts that, holding the characteristics of the housing clusters constant, the peers’ employment status should be independent of individual characteristics. To confirm this, we regress the neighbors' employment rate on the individual characteristics and the housing cluster fixed effects. Table 5 shows the results. Column (1) presents estimates from the full sample. None of the coefficients is statistically significant, and the joint tests of significance for age dummies, education dummies, and housing loss dummies are insignificant. In Column (2), the dummy for own employment status at the end of March 2011 and the timing of move-in are added; they do not correlate with the neighbors' employment rate, either. The insignificance of the own employment status means that there is no sorting on the evacuee's own employment status. Meanwhile, the insignificance of the timing of move-in implies that the random assignment was applied not only for those who moved in immediately after the completion of construction, but also for those who came in later for some reason. In Column (3), we exclude those who had already been working as of the end of March 2011 from the sample; all the coefficients remain statistically insignificant. These results reassure us of the randomness of the assignment of peers within housing clusters.

[Insert Table 5 about here]

\section{Results}

Table 6 shows the estimated coefficients of the hazard model (1). Column (1) controls only for basic demographic background characteristics such as age, educational background, and household size. In Column (2), we add dummies for housing loss and an indicator for the loss of any household members. The results are almost the same. As expected, peer $_{i}$ does not have any effect on the hazard before move-in to the temporary housing. In contrast, there is a statistically significant positive peer 
effect in the first six months after move-in. After the first six months, the effect fades away.

[Insert Table 6 about here]

To interpret the estimated $\gamma$, recall that, when peer $_{i}$ increases from $a$ to $a+b$, the right-hand side of equation (1) becomes $\exp (\gamma b)$ times larger. Given that the standard deviation of peer $r_{i}$ is 0.16 , the estimated coefficient in Column (2) implies that a one standard deviation increase in peer $r_{i}$ would make the hazard of restarting work $\exp (2.689 \times 0.16)=1.53$ times larger during the first six months.

For the sake of comparison with existing studies, we convert this estimate into the effect of a one percentage point increase in peer employment rate on an individual's own employment rate as follows. The average hazard (probability of finding a job in each period) in the first six months after move in is 1.9 percent, and one percentage point increase in peer $_{i}$ raises this to 1.9 percent $\times$ $\exp (2.689 \times 0.01)=1.95$ percent. Thus, the change in the employment rate after the first six months since move in should be $(1-0.019)^{6}-(1-0.0195)^{6}=0.0027$. This means a one percentage point increase in the peer employment rate leads to 0.27 percentage point increase in an individual's own employment probability. This is smaller than the estimated effect by Maurin and Moschion (2009), who found that a one percentage point increase in a neighbor's labor market participation increased one’s own labor market participation by about 0.6 percentage point among French women aged 2135 years.

Although only a few of the other variables are statistically significant, the signs of the estimated coefficients are reasonable. Individuals older than 60 years of age are less likely to start working, and this likely reflects the lack of employment opportunities available to them. The difference across educational background is negligible. Household size, the level of housing loss, and the loss of household members seem to have negligible effects.

Next, we examine whether the peer effect is heterogeneous across age and educational background. In particular, people older than 60 years may behave differently, given that many people start to consider retirement after age 60. It is also policy relevant since about half of the adult 
evacuees living in temporary housing are older than age 60. Regarding educational background, as surveyed by Ioannides and Loury (2004), existing studies on network and referral in job searches show that high school graduates rely on networks in a neighborhood more than college graduates do.

Table 7 shows the estimated coefficients of the interaction terms between peer $_{i}$ and dummy variables for being older than age 60 and for being vocational or university graduates. First, Column (1) shows that the peer effect is statistically significantly positive for those with a high school or less level of education. This result is consistent with previous studies on network and referral effects. However, note that the point estimate of the effect in the first six months for the more educated group is also positive and half as large as that of the less educated group. Given the smaller sample size of the more educated group, we cannot conclude whether the peer effect exists for individuals with vocational or college education.

\section{[Insert Table 7 about here]}

Second, Column (2) of Table 7 shows that the peer effect is statistically significantly positive only for those younger than age 60. Although the interaction term between peer $i$ and dummy variables for being older than 60 years is not statistically significant, the point estimate indicates that the effect of peer ${ }_{i}$ on job restating hazard is even negative for those older than age 60 .

\section{Discussion}

Finally, this section discusses two distinctive changes in the labor market in Fukushima caused by the power plant accident, and argues how they could influence the interpretation of our results. The distinctions include increases in the labor demand (Section 6.1), and the payment of financial compensation from the power plant company to the evacuees (Section 6.2). While these would not affect the identification of peer effects, they may strengthen the peer effects through peer pressure rather than information sharing. Therefore, we finally attempt to provide suggestive evidence on the underlying mechanism of peer effects in Section 6.3. 


\subsection{Employment opportunities available for evacuees}

Although the devastating earthquake and tsunami destroyed many jobs, reconstruction generated large labor demand. Figure 4 compares the active job openings to applicants ratio reported by public job-placement agencies in the Iwaki area and the national average. Before the earthquake and power plant accident, the difference between the national average and Iwaki is negligible. Then, after the quake, the ratio in Iwaki started to rise faster than the national average. It peaked at the end of 2012, and stayed significantly higher than the national average in subsequent years. Looking into this more closely, the number of job openings increased right after the power plant accident, but the number of job applicants also increased. Then, the job opening to applicant ratio gradually increased as the number of job applicants gradually decreased, while the number of job openings stayed at a high level.

While the number of job openings increased in most industries, the construction industry experienced by far the larger increase in labor demand. The number of new job openings in construction rose 2.5 fold from 2010 to 2011, ${ }^{11}$ and remain unchanged in 2012. In particular, a large number of workers were needed to clean up the radiation-affected areas, which does not require a high level of skill. Among other industries, the number of new job openings rose 1.8 fold in manufacturing and 1.6 fold in the medical and welfare industries. Furthermore, the government subsidized the firms that employed those from disaster-affected areas.

Our data also suggest that most evacuees did not have prolonged job searches. Among 174 individuals who restarted work between April 2011 and September 2013, 149 started work within three months after they started to search for a job. From another perspective, among 306 individuals who did not start to work by the time of the survey, only 49 individuals had started to search for job.

\footnotetext{
11 Number of job openings posted to Hello Work Taira, the largest public job-placement agency in Iwaki city. Retrieved from Fukushima Labour Bureau (2011, 2012, 2013).
} 


\subsection{Compensation from the Tokyo Electric Power Company (TEPCO)}

All forced evacuees received financial compensation from TEPCO. The provisional compensations were lump sums of 1,000,000 yen per household (April 2011) and 300,000 yen per person (July 2011). ${ }^{12}$ A more formal compensation scheme was then introduced in August 2011. While there are many categories of formal compensation, the two most relevant are compensations for mental distress and forgone income. The monthly compensation for mental distress is 100,000 yen per person and is supposed to be paid until the evacuation order is lifted. Thus, the expected time when this compensation is cancelled depends on the municipality of residence before the accident. The compensation for forgone income is determined by the income from the job lost due to the power plant accident. ${ }^{13}$

While TEPCO’s financial compensation to evacuees might have discouraged labor supply in general, it is unlikely to bias our estimate of the peer effect; the amount of compensation is unlikely to be correlated with the peer employment rate. Nonetheless, we conduct a robustness check.

The amount of compensation for forgone income depends on the level of income before the accident. Although income before the accident is not available, proxies for income such as gender, age, education, and occupation before the accident are available. Also, the compensation for mental distress depends on the household size, and municipality of residence before the accident. Since our main specifications already control for gender, age, education, household size, and municipality of residence (through cluster fixed effects), we added 15 job category dummies of the job before the accident. ${ }^{14}$ As shown in Table 8, the results do not change much.

\footnotetext{
12 USD 1 = JPY 83, as of April 2011.

13 Strictly speaking, the compensation for forgone income was initially defined as the difference between current income and the income before the accident. However, this scheme was criticized for discouraging labor supply because it works as a 100 percent income tax. Given this criticism, the compensation scheme was revised in March 2012 so that income from jobs held after the accident is deducted from "current income.” Thus, the compensation for forgone income might have had a negative substitution effect during the period August 2011-February 2012. However, during the other periods, such a substitution effect does not exist.

14 No job, student, agriculture, fishery, construction, manufacturing, public sector, real estate, wholesale/retail trade, hotels and restaurants, financial sector, utility, medical service, transportation, other. We did not include these dummies in the main specification because some categories have only a few observations, and thus it is unfeasible to conduct the balancing test.
} 
[Insert Table 8 about here]

\subsection{Potential underlying mechanisms}

As discussed above, it was not too difficult for the evacuees to find a job, while the financial incentive to work was low. These circumstances could potentially strengthen the peer effect driven by peer pressure against those not working. Therefore, this section attempts to provide suggestive evidence to disentangle the underlying mechanism, and contrast our result to existing studies. To the best of our knowledge, no existing studies have successfully tested the underlying mechanisms for the peer effect in employment among geographical neighbors.

There are three potential channels driving the peer effect in employment: social norms to work, information sharing, and the referral effect. First, the social norms to work make unemployed evacuees feel uncomfortable when others in the same block have a job. Such pressure may make more evacuees resume work. The second channel is information sharing. Since most of the forced evacuees were unfamiliar with job opportunities in Iwaki city when they moved in to the temporary housing, information from other evacuees who had already found jobs may play an important role in their job search. Third, given the high vacancy ratio, employers may search for workers through referrals of incumbents. That is, an evacuee who already restarted work may inform his or her neighbors of job vacancies.

It is difficult to disentangle all of the three mechanisms rigorously, given the lack of information about evacuees' current jobs. ${ }^{15}$ However, as suggestive evidence, we can test whether social norms are playing an important role, by examining the impact of the peer employment rate on the subjective well-being of the initially unemployed evacuees. The idea is as follows: if social norms to work are driving the peer effects, the employment rate among an individual's peers will have a negative effect on their subjective well-being for two reasons. First, those who have not yet

\footnotetext{
15 Information sharing is expected to improve match quality, whereas social pressure can lower the reservation wages. Thus, if we were able to estimate the effect of peer $r_{i}$ on the current earnings, we could test information sharing. Also, if we knew whether the respondents tend to start working in the same occupation as their peers, we could test the referral effect. Unfortunately, as explained in footnote 8, we were not able to ask these questions.
} 
started to work feel more uncomfortable not working when more neighbors are working. Second, even those who could find a job after the move-in may also feel unhappier if social pressure has made them take a job with unfavorable conditions. On the contrary, information sharing or the referral effect will not produce such a negative effect of the peer employment rate on subjective well-being. If there is any effect, the peer's employment rate should have a positive effect because more information gained through the employed peers enables the unemployed to find a better job.

We estimate an ordered probit model in which the dependent variable is subjective well-being compared to other evacuees and the explanatory variables are peer $_{i}$ and other control variables included in the hazard model. Respondents' subjective well-being is elicited by asking the question "Do you think happier than the other evacuees in the same cluster?"16 The possible answers range from 1 (strongly disagree) to 7 (strongly agree). Note that this variable is available only for the respondent within the survey household. Table 9 shows that the estimated coefficient of peer ${ }_{i}$ is statistically significantly negative, implying that a higher peer employment rate makes the initially unemployed evacuees unhappier, as expected if social norms to work are driving the peer effect.

[Insert Table 9 about here]

Our result is in contrast to existing studies that examined underlying mechanisms of peer effects in employment among previous co-workers (Cingano and Rosolia 2012) and three closest friends (Cappellari and Tatssiramos 2011). Both Cingano and Rosolia (2012) and Cappellari and Tatssiramos (2011) conclude that information sharing is the main cause of the observed peer effects. ${ }^{17}$ Brown and Laschever (2012) also analyze peer effects in retirement behavior among

\footnotetext{
${ }^{16}$ Unlike the standard questionnaire design used in the literature, we employ relative happiness compared with other evacuees in the same cluster for three reasons. First, we believe our question clearly captures the effects of disparity in employment status within a cluster. Second, if we employ the standard question, we can easily expect that most, if not all, respondents would answer the lowest score, given their current socio-economic and emotional situation. Therefore, we cannot observe enough variation. Finally, we believe that it is against research ethics to ask the respondents - who have obviously experienced one of the worst hardships in their lives—about to what extent they feel happy.

17 They hypothesize that, if social pressure is driving peer effects in employment, the peer employment rate should be negatively correlated with wages of new jobs because peer pressure lowers reservation wages. In contrast, if information sharing is the driving force, the correlation between the peer employment rate and wages should be positive because better information improves job search outcomes. They find the peer employment rate has a
} 
co-workers, and find supportive evidence for information sharing while retirement age norms seem to be irrelevant.

The supportive evidence for social norms that we find suggests that the underlying mechanisms of peer effects among geographical neighbors may be different from that among friends or ex-coworkers. In fact, Stutzer and Lalive (2004) show that social norms to work in a geographically defined local community shorten the duration of unemployment. Although this is just speculation, social norms may be more relevant for geographical neighbors than friends or ex-coworkers because individuals cannot avoid meeting neighbors, whereas it is easy to disconnect with friends or ex-coworkers. In addition, in the case of forced evacuees in Fukushima, such peer pressure may be strengthened by the fact that, if they want, they can find a job relatively easily thanks to the high labor demand explained in Section 6.1.

\section{Conclusion}

In this study, we exploit the random assignment of temporary housing for evacuees from the Fukushima Daiichi nuclear power plant accident to identify the effect of their neighbors' employment rate on their probability of finding a job after the evacuation. While controlling for housing cluster fixed effects, the assignment of blocks within each housing cluster is found to be completely random, and this enables us to identify the causal effect of neighbors' employment status on each resident's probability of finding a job for him or herself. We find a significantly positive peer effect that is robust to controls for various individual-level characteristics and different sample restrictions. Not only is the effect statistically significant, but its size is substantial: a one standard deviation increase in the peer employment rate increases the hazard of restarting work by 1.53 times in the first six months after move in. In addition, we find suggestive evidence consistent with the hypothesis that the observed peer effect is caused by social norms that everyone should work.

Our findings provide some useful insights into post-disaster rehabilitation policy. First, the 
significantly positive peer effect suggests that social interactions with employed individuals can significantly facilitate reemployment. In particular, segregating unemployed evacuees could impede recovery. Second, ignoring the spill-over effect might lead to under evaluation of the effectiveness of policies to promote employment of evacuees. Third, even if each cluster of evacuees is ex ante homogenous, peer effects may generate persistent disparities across the clusters by amplifying random shocks to each cluster. Fourth, the fact that social norms play an important role implies that fostering social capital may enhance resilience against natural disasters.

\section{References}

Bandiera, Oriana, Iwan Barankay, and Imran Rasul. 2010. "Social Incentives in the Workplace." The Review of Economic Studies 77(2): 417-458.

Barnhardt, Sharon, Erica Field, and Rohini Pande. 2015. "Moving to Opportunity or Isolation? Network Effects of a Randomized Housing Lottery in Urban India.” NBER Working Paper No. 21419.

Bayer, Patrick, Randi Hjalmarsson, and David Pozen. 2009. "Building Criminal Capital Behind Bars: Peer Effects in Juvenile Corrections." The Quarterly Journal of Economics 124(1): 105-147.

Bayer, Patrick, Stephen L. Ross, and Gorgio Topa. 2008. "Place of Work and Place of Residence: Informal Hiring Networks and Labor Market Outcomes." Journal of Political Economy 116(6): 1150-1196.

Borjas, George. J. 1995. "Ethnicity, Neighborhoods, and Human-Capital Externalities.” American Economic Review 85(3): 365-90.

Brown, Kristine M., and Ron A. Laschever. 2012. "When They're Sixty-Four: Peer Effects and the Timing of Retirement." American Economic Journal: Applied Economics 4(3): 90-115.

Cappellari, Lorenzo, and Konstantinos Tatsiramos. 2011. "Friends' Networks and Job Finding Rates.” Revised version of CESifo Working Paper No. 3243. 
Cingano, Federico, and Alfonso Rosolia. 2012. "People I Know: Job Search and Social Networks." Journal of Labor Economics 30(2): 291-332.

Cutler, David M., and Edward L. Glaeser. 1997. "Are Ghettos Good or Bad?" The Quarterly Journal of Economics 112(3): 827-872.

Fukushima Labour Bureau. 2011, 2012, 2013. “Rodo Shijo Nenpo (Annual report of labor market).” http://fukushima-roudoukyoku.jsite.mhlw.go.jp/jirei_toukei/koyou_toukei.html (accessed on Januray 30th, 2016)

Gould, Eric D., Victor Lavy, and M. Daniele Paserman. 2011. "Sixty Years after the Magic Carpet Ride: The Long-Run Effect of the Early Childhood Environment on Social and Economic Outcomes." Review of Economic Studies 78: 938-973.

Groen, Jeffrey A., and Anne E. Polivka. 2008. “The Effect of Hurricane Katrina on the Labor Market Outcomes of Evacuees.” The American Economic Review 98(2): 43-48.

Ioannides, Yannis M., and Linda Datcher Loury. 2004. "Job Information Networks, Neighborhood Effects, and Inequality." Journal of Economic Literature 42(4): 1056-1093.

Kling, Jeffrey R., Jeffrey B. Liebman, and Lawrence F. Katz. 2007. "Experimental Analysis of Neighborhood Effects.” Econometrica 75(1): 83-119.

Lanschever, Ron. 2009. “The Doughboys Network: Social Interactions and the Employment of World War I Veterans.” http://ssrn.com/abstract=1205543

Manski, Charles F. 1993. "Identification of Endogenous Social Effects: The Reflection Problem." The Review of Economic Studies 60(3): 531-542.

Manski, Charles. F. 2000. "Economic Analysis of Social Interactions.” Journal of Economic Perspectives 14(3): 115-136.

Mas, Alexandre, and Enrico Moretti. 2009. "Peers at Work." The American Economic Review 99(1): $112-145$.

Maurin, Eric, and Julie Moschion. 2009. "The Social Multiplier and Labor Market Participation of 
Mothers." American Economic Journal: Applied Economics 1(1): 251-272.

Sacerdote, Bruce. 2014. "Experimental and Quasi-Experimental Analysis of Peer Effects: Two Steps Forward?" Annual Review of Economics 6(1): 253-272.

Shoji, Masahiro, and Takayuki Akaike. 2014. "Social Isolation of Evacuees in Fukushima.” CIRJE Discussion Paper Series J-257.

Stutzer, Alois, and Rafael Lalive. 2004. "The Role of Social Work Norms in Job Searching and Subjective Well-Being." Journal of the European Economic Association 2(4): 696-719.

US Bureau of Labor Statistics. 2006. "The Labor Market Impact of Hurricane Katrina: An Overview." Monthly Labor Review 129(8): 3-10.

Weinberg, Bruce A., Patricia B. Reagan, and Jeffrey J. Yankow. 2004. "Do Neighborhoods Affect Hours Worked? Evidence from Longitudinal Data." Journal of Labor Economics 22(4): 891-924. 


\section{Appendix}

\section{A1. Robustness checks for alternative definition of peer groups}

As mentioned in the main text, we define an individual's peer group as neighbors living in the same blocks mainly because it is actually a good proxy of people with whom an individual actually communicates. Admittedly, however, individuals living near the border of blocks may communicate more with neighbors in the next block rather than people living in the other end of their own block. Thus, in this appendix section, we test whether our results are robust to the alternative definition of peer groups for them. Specifically, we replace peer $r_{i}$ for those living next to the border of blocks with the average employment rate of their own and adjacent blocks, weighted by the block size. For those not living next to the border and those who live in clusters with only one block, we use the original definition of peer . $_{\text {. }}$

Results are shown in Table A1. Column (1) replicates our benchmark results presented in Table 5 Column (2), and Column (2) presents the estimated coefficient of the modified peer . The

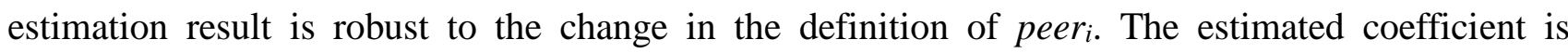
statistically significant, and a one standard deviation increase in "modified" peer ${ }_{i}$ would make the hazard of restarting work $\exp (1.691 \times 0.14)=1.27$ times larger during the first six months.

[Insert Table A1 about here]

Note that it is difficult to define peer groups without using blocks. One important merit of using the block, as the definition of a peer group, is that it is free from arbitrariness because zoning of each block is predetermined. Since the housing clusters vary in their shape and size, and our survey is not a complete survey of each cluster, it is difficult to apply unified standards such as " 20 households on the same street.”

\section{A2. Robustness checks for different sample restrictions}

Table A2 presents the results of robustness checks for different sample selections. Column (1) 
replicates Column (2) of Table V, as a benchmark. Column (2) of Table A2 limits the sample to those who moved in within two months following the completion of the housing cluster. This reduces the sample size to about 74 percent of its original size and boosts the standard error, but the size of the estimated effect in the first 6 months becomes slightly larger. These findings reassure us that our results are not driven by people who moved in later.

\section{[Insert Table A2 about here]}

Some blocks included only a few observations and peer $r_{i}$ of individuals living in such blocks may take an extreme value due to the small sample size. To confirm that our results are not driven by such small blocks, Column (3) presents estimates excluding individuals whose peer group includes less than three observations. This slightly reduces the sample size and boosts standard errors, but the estimated peer effect remains roughly the same size and significant at the 10 percent level.

Column (4) limits the sample to respondents. Motivation for this robustness check is that information on individuals other than respondents may contain more errors. Since the sample size is reduced to half, the standard errors are boosted and point estimates become noisier, but the overall pattern remains the same.

Among the 480 individuals in the sample for our main analysis, 126 were not employed before the accident, and 94 percent of them were not employed as of the survey in September 2013. Thus, most of the people who were not employed before the accident would not work regardless of the peer employment rate. To check this, Column (5) excludes individuals who were not employed before the power plant accident. The results do not change much. Note that we cannot run a separate regression for those who were not employed, since the transition to employment occurred only seven times among those who were not employed before the accident. 


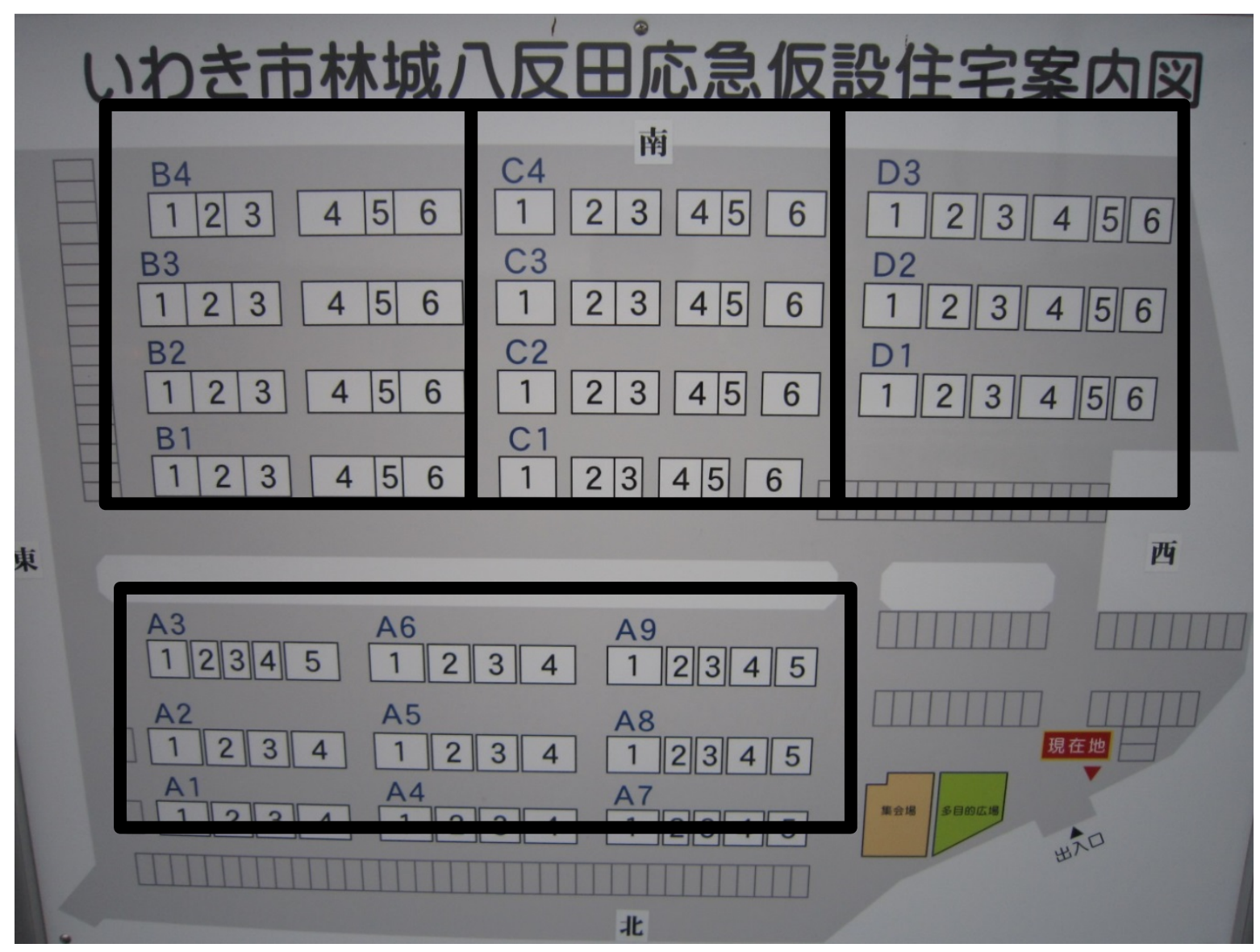

Figure 1 Example of a housing cluster map (Rinjo cluster) 


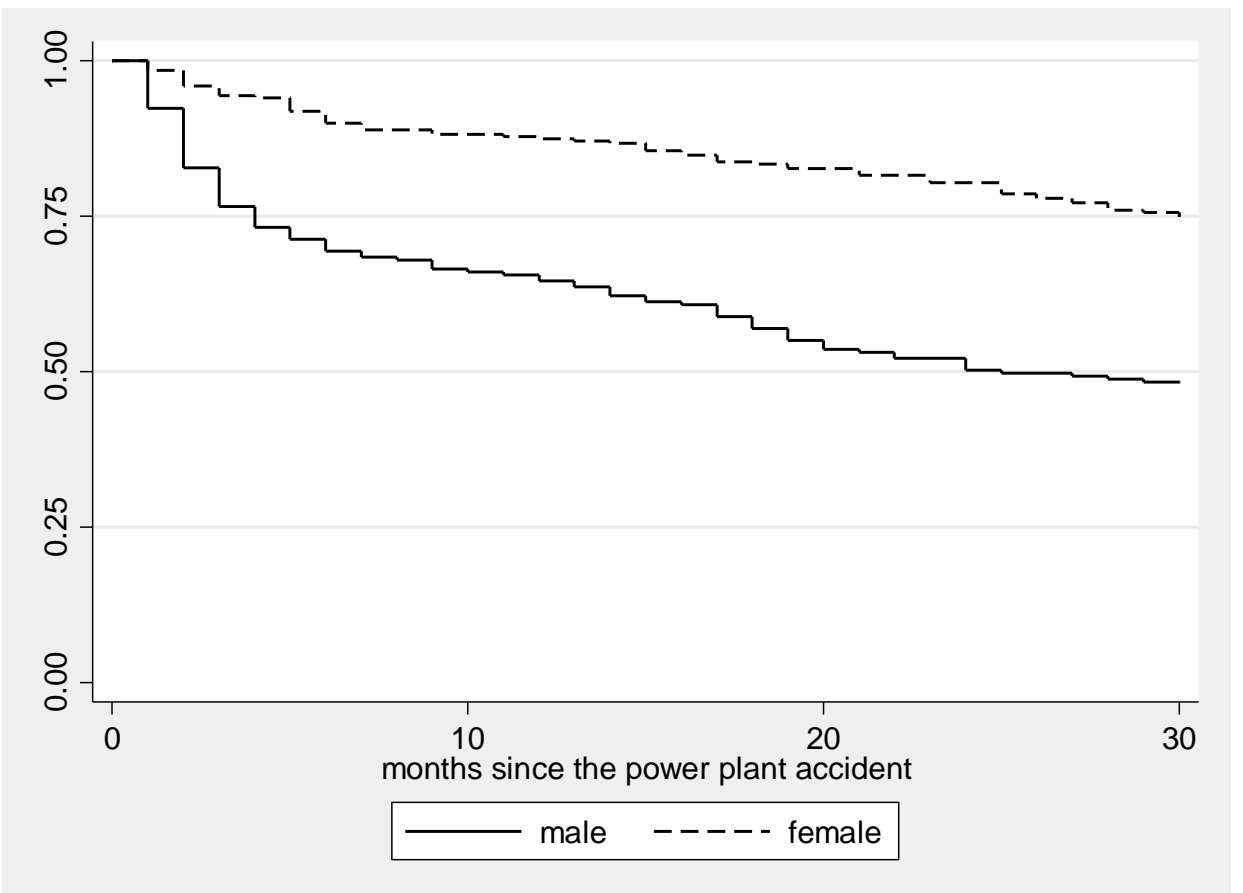

Figure 2 Kaplan-Meier survival estimates

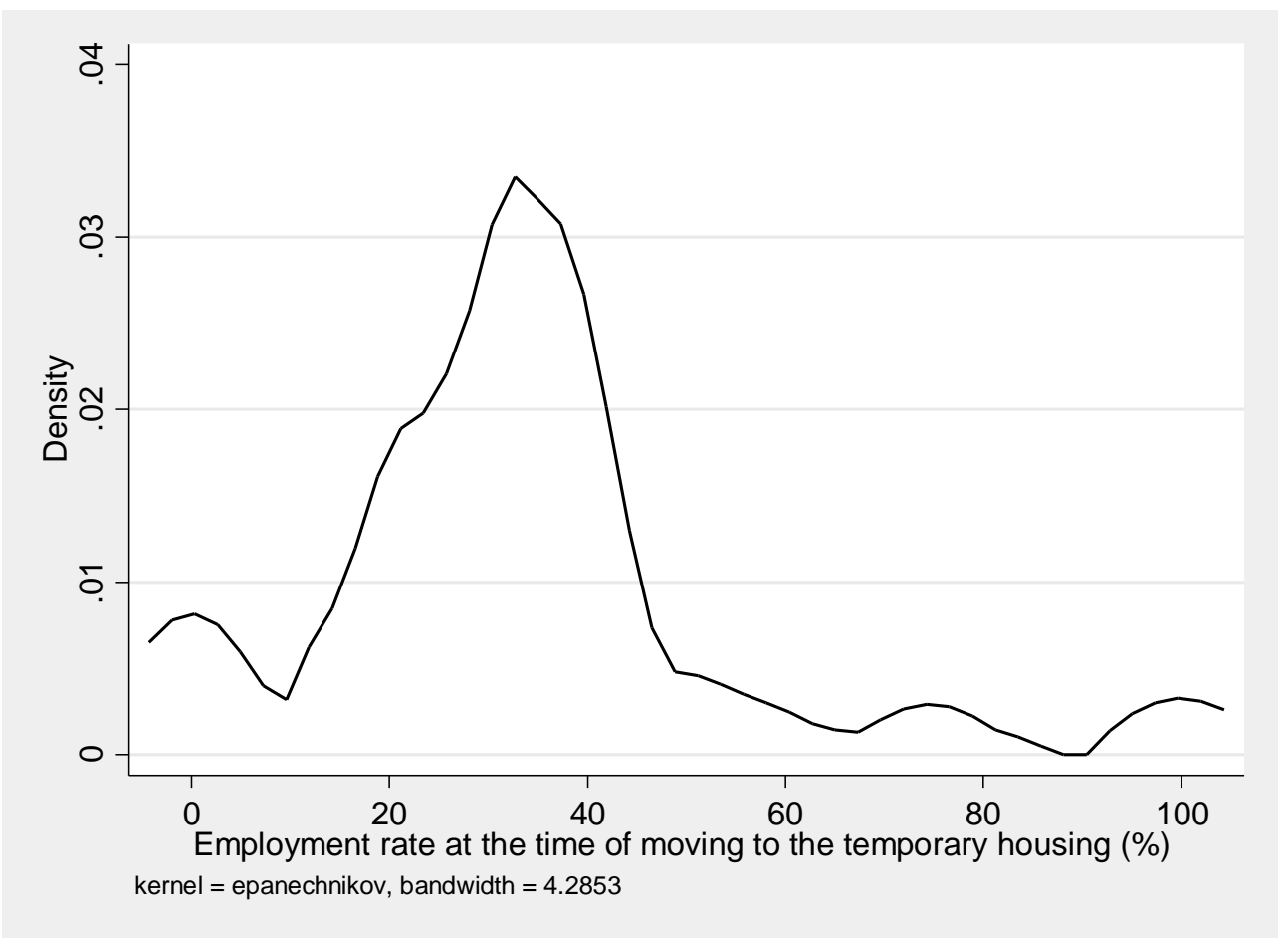

Figure 3 Kernel density of employment rate at the block level 


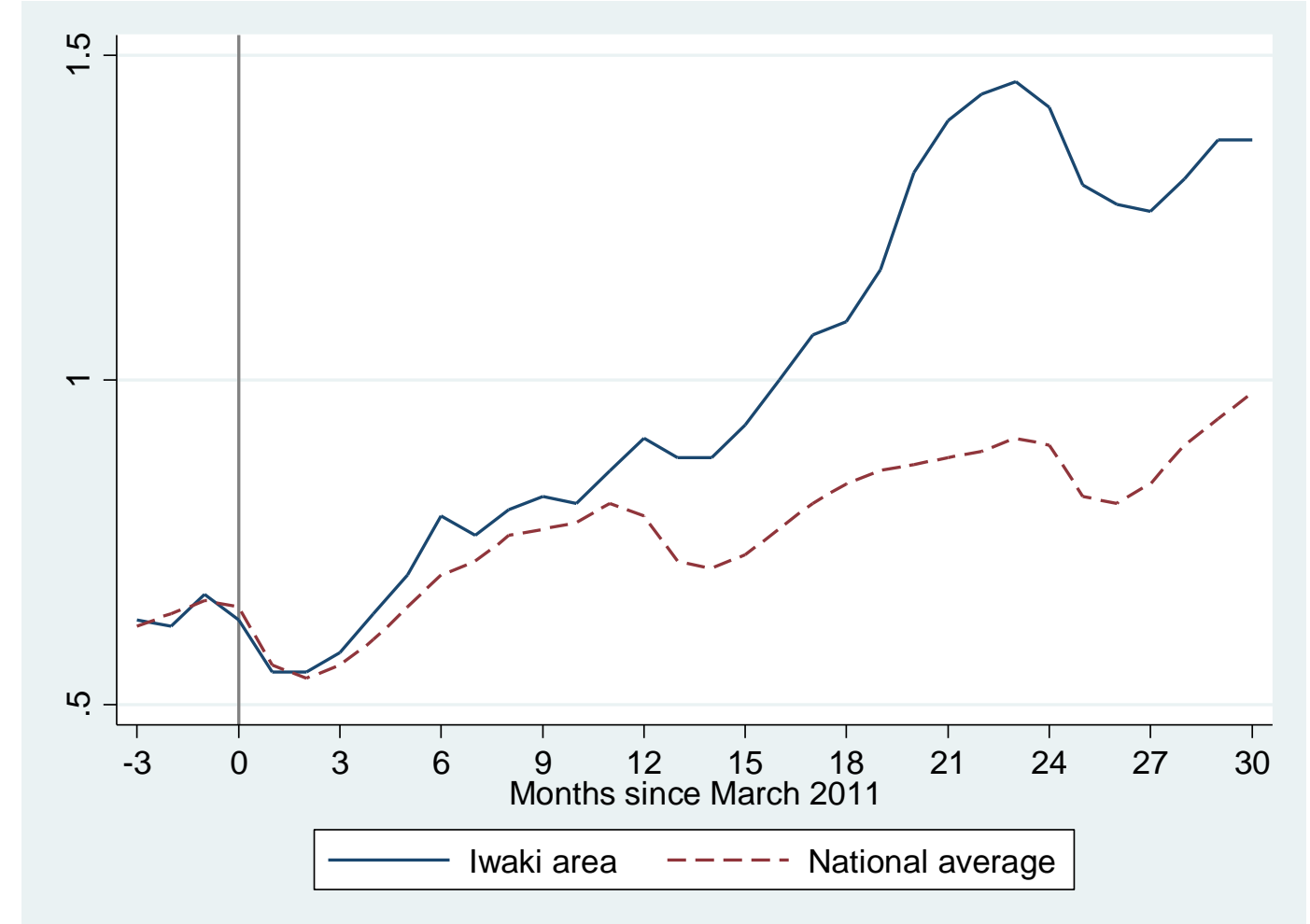

Figure 4 Active job openings to applicants ratio, December 2010-September 2013

\section{Sources}

Iwaki area: Monthly press releases by Fukushima Labour Bureau available at http://fukushima-roudoukyoku.jsite.mhlw.go.jp/jirei_toukei/koyou_toukei/koyou_situgyou.html (accessed 8/28/2015). Sum of three job-placement offices in Iwaki city.

National average: Monthly reports of the Employment Service Agency (shokugyo antei gyomu tokei), Ministry of Health, Labour and Welfare. 
Table 1: Breakdown of survey households

\begin{tabular}{lrrr}
\hline Municipality & $\begin{array}{c}\text { Sample } \\
\text { size }\end{array}$ & $\begin{array}{c}\text { Fraction in } \\
\text { the sample } \\
\text { (percentage) }\end{array}$ & $\begin{array}{c}\text { Fraction in the total number } \\
\text { of evacuees in Iwaki city } \\
\text { (percentage) }\end{array}$ \\
\hline Futaba & 30 & 5.8 & 7.4 \\
Okuma & 70 & 13.5 & 18.7 \\
Tomioka & 100 & 19.3 & 12.9 \\
Naraha & 185 & 35.8 & 33.8 \\
Kawauchi & 15 & 2.9 & 1.5 \\
Hirono & 115 & 22.2 & 21.3 \\
Iwaki* & - & -- & 4.4 \\
Others & 2 & 0.4 & \\
Missing & 1 & 0.2 & \\
\hline Total & 518 & & \\
\hline
\end{tabular}

* We exclude evacuees from tsunami-affected areas in Iwaki from our sample because their assignment to temporary housing was not based on the lottery.

Table 2: Surveyed housing clusters and number of blocks in each cluster

\begin{tabular}{cccc}
\hline \hline $\begin{array}{c}\text { Name of housing } \\
\text { cluster }\end{array}$ & Completion & $\begin{array}{c}\text { Municipality of } \\
\text { origin }\end{array}$ & $\begin{array}{c}\text { Number of } \\
\text { blocks }\end{array}$ \\
\hline Minamidai & $8 / 2011$ & Futaba & 8 \\
Shimoyada & $11 / 2011$ & Okuma & 4 \\
Kamikajiro & $5 / 2012$ & Okuma & 3 \\
Izumitamatsuyu & $9 / 2011$ & Tomioka & 4 \\
Kamiyoshima & $6 / 2011$ & Tomioka & 1 \\
Rinjo & $7 / 2012$ & Naraha & 4 \\
Uchigoshiramizu & $10 / 2011$ & Naraha & 1 \\
Takaku10 & $7 / 2011$ & Naraha & 9 \\
Takaku5 & $6 / 2011$ & Naraha & 1 \\
Takaku 9 & $7 / 2011$ & Naraha & 10 \\
Onigoe* & $10 / 2011$ & Kawauchi & 1 \\
& & Hirono & 3 \\
Takaku 2 & $6 / 2011$ & (Iwaki) & $(1)$ \\
Takaku 3 & $6 / 2011$ & Hirono & 1 \\
Takaku 4 & $6 / 2011$ & Hirono & 1 \\
\hline \hline
\end{tabular}

Note: The Kawauchi, Hirono, and Iwaki municipalities share the Onigoe cluster. Since the lottery was conducted within each municipality, in the analysis we treated blocks occupied by different municipalities as different clusters. The block occupied by Iwaki citizens is excluded from our analysis sample. 
Our sample: all individuals Population Census: all individuals aged 20-69 years as of aged 20-69 years living in the six September $2013(\mathrm{~N}=588) \quad$ municipalities as of October 2010 (shown in percentages) (shown in percentages)

\begin{tabular}{lcc}
\hline Age & & \\
20-29 years & 10 & 16 \\
$30-39$ years & 13 & 20 \\
$40-49$ years & 16 & 19 \\
$50-59$ years & 22 & 25 \\
60-69 years & 39 & 21 \\
\hline Education & & 14 \\
Junior high school & 19 & 61 \\
High school & 61 & 12 \\
Vocational/Jr college & 14 & 12 \\
University & 6 & \\
\hline \hline
\end{tabular}

Table 4: Summary statistics

All individuals Employment status at the end of March aged from 20 2011

69 years $(\mathrm{N}=\quad$ Not working Working

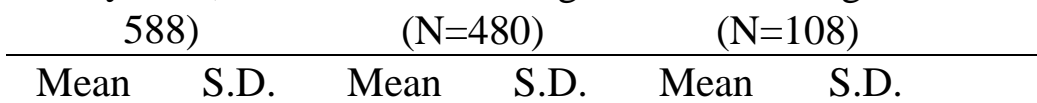

(1) (2)

(3)

(4)

(5)

(6)

\begin{tabular}{|c|c|c|c|c|c|c|c|}
\hline 1 if male & 051 & & 037 & & 079 & & $* * *$ \\
\hline Age (years) as of September 2013 & & & & & & & $* * *$ \\
\hline 20-29 (reference) & 0.10 & & 0.09 & & 0.11 & & \\
\hline $30-39$ & 0.13 & & 0.12 & & 0.15 & & \\
\hline $40-49$ & 0.16 & & 0.13 & & 0.23 & & \\
\hline $50-59$ & 0.22 & & 0.20 & & 0.28 & & \\
\hline 60-69 & 0.39 & & 0.46 & & 0.24 & & \\
\hline Education & & & & & & & $* * *$ \\
\hline Junior high school (reference) & 0.19 & & 0.19 & & 0.18 & & \\
\hline High school & 0.61 & & 0.63 & & 0.55 & & \\
\hline Vocational/Jr college & 0.14 & & 0.14 & & 0.16 & & \\
\hline University & 0.06 & & 0.04 & & 0.11 & & \\
\hline Household size & 2.83 & 1.28 & 2.74 & 0.61 & 3.01 & 0.98 & $* *$ \\
\hline \multicolumn{8}{|l|}{ Housing loss } \\
\hline None (reference) & 0.34 & & 0.34 & & 0.34 & & \\
\hline Partial & 0.40 & & 0.39 & & 0.40 & & \\
\hline Half & 0.19 & & 0.20 & & 0.16 & & \\
\hline Full & 0.08 & & 0.07 & & 0.09 & & \\
\hline $\begin{array}{l}1 \text { if lost household member(s) by the } \\
\text { tsunami }\end{array}$ & 0.06 & & 0.07 & & 0.05 & & \\
\hline \multicolumn{8}{|l|}{ Respondents' subjective well-being \# } \\
\hline Unhappier than other evacuees (1-3) & 0.15 & & 0.16 & & 0.10 & & \\
\hline
\end{tabular}




\begin{tabular}{|c|c|c|c|c|c|c|c|}
\hline Neutral (4) & 0.39 & & 0.39 & \multicolumn{4}{|c|}{0.41} \\
\hline Happier than other evacuees (5-7) & 0.46 & & \multicolumn{2}{|l|}{0.45} & \multicolumn{3}{|l|}{0.48} \\
\hline \multicolumn{8}{|l|}{ Panel B: Evacuation process } \\
\hline $\begin{array}{l}\text { Period of move-in to temporary housing } \\
\text { (months since accident) }\end{array}$ & 9.46 & 5.69 & 9.41 & 5.60 & 9.67 & 6.09 & \\
\hline \multicolumn{8}{|l|}{$\begin{array}{l}\text { The gap between construction completion } \\
\text { and move-in }\end{array}$} \\
\hline 0-2 months & 0.74 & & 0.75 & & 0.69 & & \\
\hline 3-5 months & 0.10 & & 0.09 & & 0.12 & & \\
\hline 6-9 month & 0.06 & & 0.05 & & 0.08 & & \\
\hline 10-14 months & 0.08 & & 0.09 & & 0.06 & & \\
\hline 15-29 months & 0.02 & & 0.02 & & 0.04 & & \\
\hline \multicolumn{8}{|l|}{ Panel C: Own and peers' employment status } \\
\hline $\begin{array}{l}\text { Already working at the time of moving } \\
\text { into the temporary housing }\end{array}$ & 0.33 & & 0.18 & & 1 & & $* * *$ \\
\hline Males & 0.51 & & 0.30 & & 1 & & $* * *$ \\
\hline Females & 0.14 & & 0.08 & & 1 & & $* * *$ \\
\hline Restarted work by September 2013 & 0.48 & & 0.36 & & 1 & & \\
\hline Size of peer group in the same block & 15.6 & 8.4 & 15.7 & 8.4 & 15.5 & 8.6 & \\
\hline $\begin{array}{l}\text { Percentage peers already started to work } \\
\text { before they moved in }\left(\text { peer }_{i}\right)\end{array}$ & 0.32 & 0.16 & 0.31 & 0.15 & 0.33 & 0.20 & \\
\hline
\end{tabular}


Table 5: Test for exogeneity of neighbors' employment status

Dependent variable: Percentage of neighbors who had started working before moving into temporary housing

\begin{tabular}{|c|c|c|c|}
\hline & \multicolumn{2}{|c|}{ All } & \multirow{2}{*}{$\begin{array}{l}\text { Not working at the end } \\
\text { of March } 2011 \\
\text { (3) }\end{array}$} \\
\hline & $(1)$ & $(2)$ & \\
\hline \multirow[t]{2}{*}{ Male } & -0.01 & -0.009 & -0.008 \\
\hline & {$[0.010]$} & [0.009] & {$[0.011]$} \\
\hline \multirow[t]{2}{*}{ Age 30-39 years } & -0.015 & -0.015 & -0.02 \\
\hline & {$[0.031]$} & {$[0.031]$} & {$[0.034]$} \\
\hline \multirow[t]{2}{*}{ Age $40-49$ years } & 0.043 & 0.044 & 0.040 \\
\hline & [0.029] & [0.028] & [0.032] \\
\hline \multirow[t]{2}{*}{ Age 50-59 years } & -0.002 & -0.002 & -0.004 \\
\hline & [0.022] & [0.023] & [0.027] \\
\hline \multirow[t]{2}{*}{ Age 60-69 years } & -0.005 & -0.005 & 0.006 \\
\hline & [0.025] & {$[0.026]$} & {$[0.027]$} \\
\hline \multirow[t]{2}{*}{ High school } & -0.002 & -0.002 & -0.001 \\
\hline & {$[0.016]$} & {$[0.017]$} & {$[0.015]$} \\
\hline \multirow[t]{2}{*}{ Vocational/Jr college } & -0.012 & -0.011 & -0.011 \\
\hline & {$[0.030]$} & [0.031] & [0.033] \\
\hline \multirow[t]{2}{*}{ University } & 0.004 & 0.005 & 0.036 \\
\hline & [0.039] & [0.043] & {$[0.048]$} \\
\hline \multirow[t]{2}{*}{ Household size } & -0.002 & -0.002 & 0.004 \\
\hline & [0.007] & [0.007] & {$[0.004]$} \\
\hline \multirow[t]{2}{*}{ Housing loss: partial } & -0.01 & -0.011 & -0.016 \\
\hline & [0.013] & {$[0.015]$} & [0.012] \\
\hline \multirow[t]{2}{*}{ Housing loss: half } & 0.008 & 0.007 & 0.001 \\
\hline & {$[0.040]$} & {$[0.040]$} & {$[0.034]$} \\
\hline \multirow[t]{2}{*}{ Housing loss: full } & -0.026 & -0.027 & -0.007 \\
\hline & {$[0.041]$} & [0.042] & {$[0.035]$} \\
\hline \multirow{2}{*}{$\begin{array}{l}\text { Dummy for having lost household member(s) } \\
\text { by the tsunami }\end{array}$} & -0.018 & -0.018 & -0.009 \\
\hline & [0.031] & [0.032] & {$[0.031]$} \\
\hline \multirow{2}{*}{$\begin{array}{l}\text { Already restarted working by the end of } \\
\text { March } 2011\end{array}$} & & -0.005 & \\
\hline & & {$[0.025]$} & \\
\hline \multirow{2}{*}{$\begin{array}{l}\text { Gap between construction completion } \\
\text { and move-in }\end{array}$} & & 0.000 & \\
\hline & & [0.002] & \\
\hline \multicolumn{4}{|l|}{ P-values of F-test for joint significance } \\
\hline Age dummies & 0.36 & 0.41 & 0.29 \\
\hline Education dummies & 0.61 & 0.65 & 0.46 \\
\hline Housing loss dummies & 0.74 & 0.78 & 0.50 \\
\hline Observations & 588 & 588 & 480 \\
\hline R-squared & 0.20 & 0.20 & 0.23 \\
\hline
\end{tabular}

$* * * \mathrm{p}<0.01, * * \mathrm{p}<0.05, * \mathrm{p}<0.1$. Housing cluster fixed effects are included. Standard errors clustered at the housing cluster are in brackets. 
(1)

(2)

Percentage of neighbors who had restarted working before moving into the temporary housing (peer $\mathrm{i}_{\mathrm{i}}$ )

$\times$ before move in

$\times 0-5$ th month after move in

$0.180 \quad 0.197$

$\times 6-11$ th month after move in

[1.462]

[1.581]

$x 6-11$ th month after move in

$2.645^{* * *} \quad 2.689 * * *$

$\times$ more than 1 year after move-in

[0.946] [1.033]

$0.701 \quad 0.813$

[0.854] [0.939]

$0.487 \quad 0.444$

[1.236] [1.212]

Age 30-39 years

$0.109 \quad 0.148$

[0.307] [0.329]

Age 40-49 years

$0.279 \quad 0.301$

[0.339] [0.360]

Age 50-59 years

$0.189 \quad 0.204$

[0.299] [0.318]

Age 60-69 years

$-0.873 * * \quad-0.848 *$

High school

[0.431]

[0.456]

$-0.212 \quad-0.204$

[0.175] [0.151]

Vocational/Jr college

$-0.235 \quad-0.263$

University

[0.250]

[0.274]

$0.135 \quad 0.067$

[0.244] [0.282]

Household size

$0.065 \quad 0.062$

[0.087] [0.081]

Housing loss: partial

[0.185]

$-0.342$

[0.235]

$-0.015$

Housing loss: full

$-0.375$

Dummy for having lost household member(s) by the tsunami [0.402]

Number of observations 10,944 10,944

Number of individuals 480 480

*** $\mathrm{p}<0.01, * * \mathrm{p}<0.05, * \mathrm{p}<0.1$. Standard errors clustered at the housing cluster are in brackets. Both specifications include controls for housing cluster fixed effects and dummy for $0-5$ th month after move in, 6 -11th month after move in, and more than 1 year after move in. 
Coefficient of percentage of neighbors who had restarted working before moving into the temporary housing (peeri) interacted with:

High school or less xbefore move in

0.859

[1.423]

High school or less $\times 0-5$ th month after move in $3.027 * * *$ $\times 6-11$ th month after move in 0.675

[1.732]

0.396

[2.151] $\times$ more than 1 year after move in

Younger than age 60

$\times$ before move in

$3.756 * * *$

Younger than age 60

$\times 0-5$ th month after move in

Younger than age 60

$\times 6-11$ th month after move in

Younger than age 60

$\times$ more than 1 year after move in

60 years or older

$\times$ before move in

$\times 0$-5th month after move in

$\times 6-11$ th month after move in $-0.858$

60 years or older [2.050] $\times$ more than 1 year after move in

Number of observations

Number of individuals 10,944

*** $\mathrm{p}<0.01,{ }^{* *} \mathrm{p}<0.05,{ }^{*} \mathrm{p}<0.1$. Standard errors clustered at the housing cluster are in brackets. Both specifications include the same explanatory variables as in Column (2) of Table V. 
Percentage of neighbors who had restarted working before moving into the temporary housing (peer $\mathrm{i}_{\mathrm{i}}$ )

$\times$ before move in

$\times 0-5$ th month after move in $2.689 * * * \quad 2.008 * *$

$\times 6-11$ th month after move in

0.813

[0.939]

$\times$ more than 1 year after move in

0.444

[1.212] [1.317]

Dummies for job before the power plant accident

No

Number of observations

10,944

Yes

Number of individuals

480 478

Table 9: Test for social norms as mechanisms of peer effects

Ordered probit model; dependent variable = happiness compared to other evacuees (1-7 scale)

Percentage of neighbors who had restarted working before moving into the temporary housing (peer $\left.r_{\mathrm{i}}\right)$

*** $\mathrm{p}<0.01,{ }^{* *} \mathrm{p}<0.05, * \mathrm{p}<0.1$. Standard errors clustered at the housing cluster are in brackets. Other explanatory variables are the same as those in Column (2) of Table V and female dummy. 
Table A1: Robustness checks for different definition of peer group

(1) People living in the same block, excluding own family members (replication of Column (2) of Table 5)

(2) Modified peer : For those living in housing units adjacent to the next block, the average of own and adjacent blocks weighted by the block size.

\begin{tabular}{|c|c|c|}
\hline & $(1)$ & (2) \\
\hline Definition of peer : & Original & Modified \\
\hline \multirow[t]{2}{*}{ Peer $_{i} \times$ before move in $^{2}$} & 0.197 & -0.546 \\
\hline & {$[1.581]$} & [1.107] \\
\hline \multirow[t]{2}{*}{ Peer $_{i} \times 0-5$ th month after move in } & $2.689 * * *$ & $1.691^{*}$ \\
\hline & [1.033] & [0.965] \\
\hline \multirow[t]{2}{*}{ Peer $_{i} \times 6-11$ th month after move in } & 0.813 & 0.880 \\
\hline & [0.939] & [1.296] \\
\hline \multirow[t]{2}{*}{ Peer $_{i} \times$ more than 1 year after move in } & 0.444 & 0.287 \\
\hline & [1.212] & [1.420] \\
\hline Number of observations & 10,944 & 10,944 \\
\hline Number of individuals & 480 & 480 \\
\hline
\end{tabular}

Table A2: Robustness checks for different sample restrictions

(1) All individuals aged 20-69 years (replication of Column (2) of Table 5)

(2) Individuals who moved in within two months after completion of the housing cluster

(3) Individuals whose peer group includes three or more observations

(4) Respondents only

(5) Excluding individuals who were not employed before the power plant accident

\begin{tabular}{lccccc}
\hline \hline & $(1)$ & $(2)$ & $(3)$ & $(4)$ & $(5)$ \\
\hline Peer $\times$ before move in & 0.197 & -0.039 & 0.167 & 0.016 & -0.020 \\
& {$[1.581]$} & {$[1.761]$} & {$[1.928]$} & {$[2.060]$} & {$[1.364]$} \\
Peer $\times$ 0-5th month after move in & $2.689^{* * *}$ & $3.363^{* * *}$ & $2.247^{*}$ & $2.724^{*}$ & $2.434^{* *}$ \\
& {$[1.033]$} & {$[1.212]$} & {$[1.255]$} & {$[1.399]$} & {$[1.016]$} \\
Peer $\times 6$-11th month after move in & 0.813 & 0.832 & 1.505 & -0.604 & 0.830 \\
& {$[0.939]$} & {$[1.428]$} & {$[1.003]$} & {$[2.527]$} & {$[0.983]$} \\
Peer $\times$ more than 1 year after move in & 0.444 & -0.513 & -0.36 & 1.407 & -0.134 \\
& {$[1.212]$} & {$[1.327]$} & {$[1.360]$} & {$[2.039]$} & {$[1.759]$} \\
\hline Number of observations & 10,944 & 8,395 & 10,429 & 6,403 & 7,214 \\
Number of individuals & 480 & 360 & 460 & 265 & 354 \\
\hline \hline
\end{tabular}

$* * * \mathrm{p}<0.01, * * \mathrm{p}<0.05, * \mathrm{p}<0.1$. Standard errors clustered at the housing cluster are in brackets. Other explanatory variables are the same as those in Column (2) of Table V. 